\title{
Conjugal transfer of plasmid pMV158: uncoupling of the pMV158 origin of transfer from the mobilization gene mobM, and modulation of pMV158 transfer in Escherichia coli mediated by IncP plasmids
}

María Eugenia Farías and Manuel Espinosa

Author for correspondence: Manuel Espinosa. Tel: +34 915611800. Fax: + 34915627518.
e-mail: mespinosa@cib.csic.es

Centro de Investigaciones Biológicas, CSIC, Velázquez, 144 E-28006 Madrid, Spain

\begin{abstract}
The streptococcal plasmid pMV158 encodes a gene cassette involved in its mobilization by large conjugative plasmids. Two elements compose this region: i) the mobM gene, encoding the MobM protein that initiates transfer, and ii) the origin of transfer, oriT, which is the target of MobM. In vitro, MobM protein introduces a specific nick within the pMV158-oriT region on supercoiled pMV158 DNA. This paper reports the uncoupling of the oriT and the mobM gene, the latter being placed under the control of an inducible promoter. Upon induction, the vector containing pMV158-oriT was transferred in Escherichia coli matings at a moderate frequency whereas, in vitro, purified MobM protein efficiently cleaved the vector harbouring the pMV158-oriT. Transfer of this vector, as well as transfer of pMV158 in E. coli, required the presence of either the IncW R388 or the IncP RP4 plasmids as auxiliary plasmids. Dissection of the functions encoded by RP4 showed that the traG and traF genes were essential for pMV158 mobilization.
\end{abstract}

Keywords: plasmid RP4, streptococcal pMV158 transfer, mobilization protein, oriT

\section{INTRODUCTION}

Plasmid-mediated conjugation involves the unidirectional transfer of a single DNA strand (the socalled T-strand) from a donor to a recipient cell. This process is initiated at a unique plasmid site (the nic site), which is located within the origin of transfer, the oriT (Lanka \& Wilkins, 1995). The initiation reaction is catalysed by a plasmid-encoded, site-specific DNA relaxase (generically termed Tra or Mob) which exerts a nucleophilic attack at the phosphodiester bond of a dinucleotide, located within the oriT (Pansegrau \& Lanka, 1996). Transfer of the T-strand is assumed to have an overall $5^{\prime}-3^{\prime}$ polarity, and requires the assembly of a multiprotein-DNA complex, the relaxosome (Lanka \& Wilkins, 1995). Inside the recipient cell, complementary strand synthesis occurs mediated by plasmid-encoded DNA primases which are transferred with the donor DNA (reviewed by Lanka \& Wilkins, 1995), or by transcription from single-stranded DNA promoters (Bates et al., 1999; Masai \& Arai, 1997).
Many small multicopy plasmids, like those replicating by the rolling circle mechanism, may carry a cassette of gene(s) involved in their mobilization by larger plasmids. Such is the case of the streptococcal plasmid pMV158 (Burdett, 1980), in which the MobM protein is involved in pMV158 mobilization mediated by plasmids of the Inc18 family, like pIP501 or pAM $\beta 1$ (Priebe \& Lacks, 1989). In vitro, purified MobM protein cleaves the $5^{\prime}$ GpT-3' dinucleotide (between pMV158 coordinates 3591 and 3592) in the sequence $5^{\prime}$-AGTGTG $\downarrow$ TTA-3' ( $\downarrow$ being the site of cleavage) within the plasmid oriT (Guzmán \& Espinosa, 1997). The DNA-binding sequence of protein MobM has been shown to span $28 \mathrm{nt}$ within the in vitro defined oriT, a DNA region that includes an inversely repeated sequence, termed IR2 (Grohmann et al., 1999). In addition, the $5^{\prime}$ and $3^{\prime}$ ends of the nick introduced by MobM have been determined i) by in vitro assays with purified protein (Guzmán and Espinosa, 1997) and ii) in exponentially growing Streptococcus pneumoniae cells harbouring pMV158 (Grohmann et al., 1997). In vitro cleavage of DNA from 
pMV158 by purified MobM protein required a supercoiled or single-stranded substrate, indicating that the nic site should be exposed in a single-stranded DNA configuration for MobM-dependent cleavage (Grohmann et al., 1999).

In spite of the above in vitro findings, a direct definition of the in vivo functionality of pMV158-oriT has not been tested. This functionality has been addressed here by uncoupling the mobM gene from the oriT region and showing that transfer did occur in these conditions. To this end we have cloned pMV158-oriT into an Escherichia coli plasmid vector, whereas the mobM gene was cloned into a compatible plasmid, and placed under the control of an inducible promoter. Upon induction, transfer of the pMV158-oriT-containing vector was observed at a moderately high frequency when the IncP plasmid RP4 provided the conjugative machinery (Pansegrau et al., 1994). In addition, RP4 or the IncW plasmid R388 were able to mobilize pMV158 at a frequency similar to that found when pMV158 was mobilized in S. pneumoniae (Priebe \& Lacks, 1989) or in Lactococcus lactis (Farías et al., 1999) by plasmids pIP501 or pAM $\beta 1$ (Wang \& Macrina, 1995 and references therein). Plasmids harbouring genes involved in the RP4 transfer systems were able to mobilize pMV158, except when the RP4-traG or the traF genes were absent, indicating that these gene products participate in the mobilization of pMV158.

\section{METHODS}

Bacterial strains and plasmids. The E. coli BL21(DE3)/pET5 plasmid system (a gift of B. Studier, Brookhaven National Laboratory, NY, USA) was employed to construct plasmid pLGM2, this latter used for overproduction of MobM (Guzmán \& Espinosa, 1997). The same bacterial strain was used as the host to construct the oriT-containing plasmid pNLF4 and as the donor strain in some of the mobilization assays, whereas E. coli LE392 or DH5 $\alpha$ (Sambrook et al., 1989) was used in the transfer of pMV158 mediated by RP4 or R388, respectively. When RP4 derivatives were employed, the donor strain was HB101, as described by Balzer et al. (1994). In all assays we used as recipient E. coli HMS174, encoding chromosomal resistance to rifampicin (Campbell et al., 1978). Cultures were grown at $37^{\circ} \mathrm{C}$ in TY medium, and resistance to rifampicin $\left(50 \mu \mathrm{g} \mathrm{ml}^{-1}\right)$ was applied for the recipient strain in conjugation experiments. Plasmid pLGM2 contains two tandem copies of the pMV158-mobM gene (devoid of the oriT) placed under the control of promoter $\phi 10$ of bacteriophage T7, so that synthesis of MobM is inducible by IPTG. Other plasmids used and the selection for antibiotic resistance are listed in Table 1.

DNA preparation and transformation. Extraction and purification of plasmid DNAs from E. coli were performed using the Qiagen kit (Qiagen), whereas purified pMV158 DNA from $S$. pneumoniae was prepared as described by del Solar et al. (1987). Restriction endonucleases, the Klenow fragment of DNA polymerase I (PolIK) and DNA ligase were purchased from New England Biolabs and were used as specified by the suppliers. Restriction fragments employed for cloning experiments were purified from agarose gels by the phenol extraction procedure (Sambrook et al., 1989). Preparation of E. coli competent cells to electroporate with plasmid DNAs were performed by standard methods (Sambrook et al., 1989). E. coli BL21(DE3)/pLGM2 was sequentially electrotransformed with plasmids RP4 and pNLF4, and the plasmid content was checked by agarose gel electrophoresis.

Filter matings. Cells harbouring plasmids (donors) were grown to $3 \times 10^{8}$ c.f.u. $\mathrm{ml}^{-1}$ and $200 \mu \mathrm{l}$ of the cultures was mixed with $2 \mathrm{ml}$ of the recipient E. coli HMS174, grown to the same cell density. In the case of strain BL21(DE3) harbouring the three plasmids (RP4, pNLF4 and pLGM2), when the cultures reached the above density, they were induced with various concentrations of IPTG for several time periods, and the same strain HMS174 was used as recipient. In all cases, and to mimic the mating assays that we routinely perform among Gram-positive bacteria, the cell mixtures were filtered onto sterile $13 \mathrm{~mm}$ diameter nitrocellulose filters $(0 \cdot 22 \mu \mathrm{m}$, Millipore), placed cell-side up on TY-agar plates and incubated at $37^{\circ} \mathrm{C}$ for $4 \mathrm{~h}$. Cells were removed by washing the

\section{Table 1. Bacterial plasmids used}

$\mathrm{Ap}^{\mathrm{R}}$, ampicillin resistant $\mathrm{Cm}^{\mathrm{R}}$, chloramphenicol resistant $\mathrm{Km}^{\mathrm{R}}$, kanamycin resistant; $\mathrm{Tc}^{\mathrm{R}}$, tetracycline resistant.

\begin{tabular}{|c|c|c|c|}
\hline Plasmid & Relevant markers & $\begin{array}{l}\text { Selection applied } \\
\left(\mu \mathrm{g} \mathrm{ml}^{-1}\right)\end{array}$ & Source or reference \\
\hline pMV158 & $\mathrm{Tc}^{\mathrm{R}}$, mobM, oriT & 10 & Burdett $(1980)$ \\
\hline pLS1 & $\mathrm{Tc}^{\mathrm{R}}, \Delta m o b M, \Delta o r i \mathrm{~T}$ & 10 & Lacks et al. (1986) \\
\hline pLGM2 & $\mathrm{Ap}^{\mathrm{R}}, \phi 10:: m o b M$ & 200 & Guzmán \& Espinosa (1997) \\
\hline pACYC184 & $\mathrm{Cm}^{\mathrm{R}}$ & 35 & A gift of New England Biolabs \\
\hline pNLF4 & $\mathrm{Cm}^{\mathrm{R}}$ pMV158-oriT & 35 & This work \\
\hline RP4 & $\mathrm{Km}^{\mathrm{R}}$ & 20 & Pansegrau et al. (1994) \\
\hline pDB126 & $\mathrm{Cm}^{\mathrm{R}}$ & 10 & Balzer et al. (1994) \\
\hline pBD127 & $\mathrm{Cm}^{\mathrm{R}}$ & 10 & Balzer et al. (1994) \\
\hline pBD128 & $\mathrm{Cm}^{\mathrm{R}}$ & 10 & Balzer et al. (1994) \\
\hline pBD129 & $\mathrm{Cm}^{\mathrm{R}}$ & 10 & Balzer et al. (1994) \\
\hline pSU2007 & $\begin{array}{c}\mathrm{Km}^{\mathrm{R}} \text { derivative } \\
\text { of } \mathrm{R} 388\end{array}$ & 30 & Bolland et al. (1990) \\
\hline
\end{tabular}


(a)

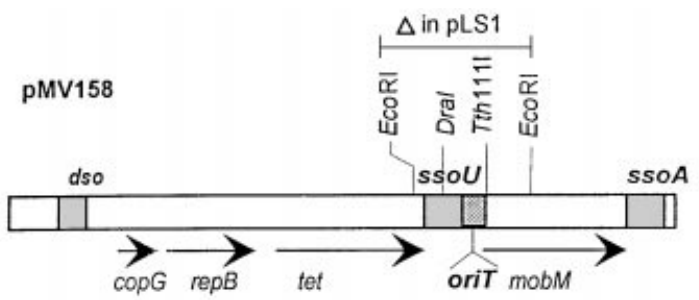

(b)

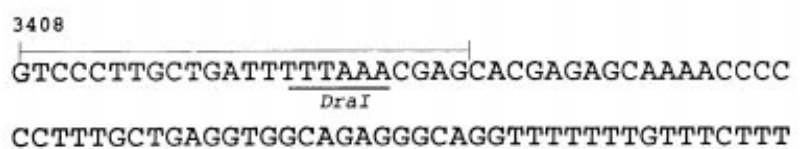

CCTTTGCTGAGGTGGCAGAGGGCAGGTTTTTTTGTTTCTTT

TTTCTCGTAAAAAAAAGAAAGGTCTTAAAGGTTTTATGGTT

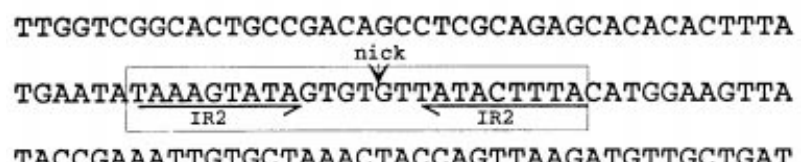

TACCGAAATTGTGCTAAACTACCAGTTAAGATGTTGCTGAT

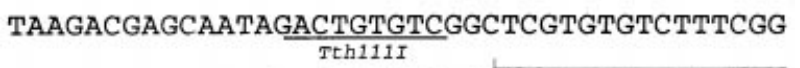

TAATCGAAAGACAAGTCTTAAGGAGGGAAATCTATGAGTTA

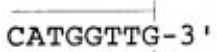

3743

(c)

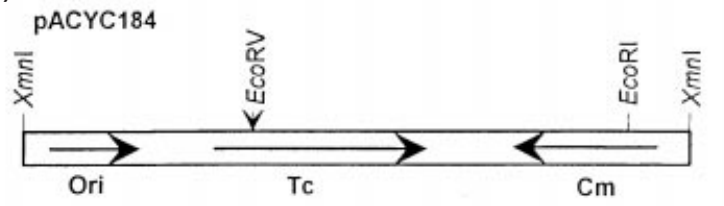

Fig. 1. The oriT region of plasmid pMV158. (a) Schematic map of plasmid pMV158. Regions indicated are: origins of replication of the leading ( $d s o$ ) and lagging (sso) strands (stippled); oriT, region containing the in vitro defined origin of transfer (shadowed). Relevant genes are: copG and repB, involved in plasmid replication and its control; tet, involved in tetracycline resistance and $m o b M$, encoding the mobilization protein, MobM. Relevant restriction sites are indicated. The EcoRI fragment, missing in the pMV158-derivative plasmid pLS1, is also indicated. (b) The region encompassing the pMV158-oriT, between coordinates 3408 and 3743. Relevant features are the MobM-mediated nick site (vertical arrow) and the region protected by MobM from DNase I cleavage (boxed), which encompass the inverted repeat IR2; the mobM initiation codon and its ribosome-binding site (SD, underlined); relevant restriction sites (underlined) and oligonucleotides (thin lines on top of the sequence) used to amplify the pMV158-oriT region. (c) Schematic map of the vector pACYC184, indicating the replication region (Ori), and genes encoding resistance to chloramphenicol $(\mathrm{Cm})$ and tetracycline (Tc). The single EcoRV site, used to clone the Dral-Tth111l region of pMV158 (b), is indicated by a vertical arrow; other relevant restriction sites are also indicated.

filters with $10 \mathrm{mM} \mathrm{MgCl}_{2}, 2 \mu \mathrm{g}$ bovine serum albumin $\mathrm{ml}^{-1}$ and $10 \%(\mathrm{v} / \mathrm{v})$ glycerol, and plated on the appropriate solid media containing the selective antibiotics. Transconjugants were allowed to grow for $18 \mathrm{~h}$. All experiments were performed in the presence of DNase I $\left(100 \mu \mathrm{g} \mathrm{ml}{ }^{-1}\right)$. Frequency of conjugation was expressed as the ratio between the number of transconjugants per donor cell and the values are the mean of three independent experiments.

Cloning of the pMV158-oriT. The EcoRV restriction site of plasmid pACYC184 was used to clone the pMV158 region encompassing the in vitro defined oriT. This region was obtained by PCR amplification with the following primers: 5'-GTCCCTTGCTGATTTTTAAACGAG-3' (coordinates 3408-3431 of pMV158) and 5'-CAACCATGTAACTCATAGATTTCC-3' (coordinates 3720-3743).

The former primer contains a DraI restriction site (underlined), whereas the second includes the first codons of gene mobM (see Fig. 1). The resulting amplified DNA harbours a Tth111I restriction site, so that it was digested with DraI and Tth111I. The protruding Tth111I-generated ends were filled in with PolIK enzyme, and the resulting $247 \mathrm{bp}$ DNA fragment was ligated to DNA from plasmid pACYC184 linearized at its single EcoRV site. The ligation mixture was used to electroporate E. coli BL21(DE3), and clones harbouring plasmids of the expected size were selected for further characterization. Plasmid DNA from one clone harbouring the desired recombinant plasmid (termed pNLF4), was isolated and the integrity of the cloned region was verified by determination of its nucleotide sequence on an automated sequencer (ABI 373A) and the dyedeoxynucleotide termination procedure (Applied Biosystems). Finally, DNA from pNLF4 was used to electroporate E. coli BL21(DE3) harbouring plasmids pLGM2 and RP4.

In vitro activity of MobM. Standard reaction mixtures $(20 \mu \mathrm{l})$ contained supercoiled pNLF4 DNA (200 ng) in buffer (25 mM Tris/ $\mathrm{HCl}, \mathrm{pH} 7 \cdot 6,0 \cdot 1 \mathrm{mM}$ EDTA, $15 \mathrm{mM} \mathrm{MgCl}_{2}, 10 \%$, v/v, glycerol, $1 \mathrm{mM}$ dithiothreitol) to which bovine serum albumin $\left(30 \mu \mathrm{g} \mathrm{ml}^{-1}\right)$ and purified MobM protein (25 or $50 \mathrm{ng}$ ) were added. Samples were incubated at $30^{\circ} \mathrm{C}$ for $30 \mathrm{~min}$. Reactions were stopped by addition of $0.5 \%$ SDS and proteinase $\mathrm{K}$ $\left(100 \mu \mathrm{g} \mathrm{ml}^{-1}\right)$, followed by incubation for $30 \mathrm{~min}$. Mixtures were loaded on $0.8 \%$ agarose gels and subjected to electrophoresis at $4 \mathrm{~V} \mathrm{~cm}^{-1}, 4{ }^{\circ} \mathrm{C}, 16 \mathrm{~h}$ in TE buffer. The bands corresponding to supercoiled and to relaxed plasmid DNA forms were quantified by the use of the Gel Doc-2000 equipment and Quantity One software (Bio-Rad).

\section{RESULTS AND DISCUSSION}

\section{Mobilization of pMV158 by RP4}

Plasmid pMV158 is able to replicate in E. coli (del Solar et al., 1987), and it has been mobilized between species of Gram-positive bacteria by means of plasmids of the Inc18 family (Priebe \& Lacks, 1989; van der Lelie et al., 1990). In addition, the MobM protein has been shown to be functional in two Gram-positive bacteria: i) $S$. pneumoniae, as judged by determination of the nick site in vivo (Grohmann et al., 1997), and ii) Lactococcus lactis, where the intracellular concentration of MobM has been measured (Farías et al., 1999).

A number of plasmids and transposons were shown to be transferable by conjugation between Gram-positive and Gram-negative bacteria by means of the functions supplied by plasmids of the IncP family (Bertram et al., 1991; Smith et al., 1980; Trieu-Cuot et al., 1987). To test whether conjugal transfer of pMV158 occurred in E. coli, cells harbouring plasmid RP4 were transformed 
Table 2. Mobilization of pMV158 mediated by RP4

ND, None detected.

\begin{tabular}{|lccc|}
\hline Mobilizable plasmid & Auxiliary plasmid & \multicolumn{2}{c|}{ Mobilization frequencies for* } \\
\cline { 3 - 4 } & & pMV158 & RP4 \\
& & ND & $1.6 \times 10^{-2}$ \\
None & RP4 & $1 \cdot 3 \times 10^{-5}$ & $2.0 \times 10^{-2}$ \\
pMV158 & RP4 & ND & $1.5 \times 10^{-2}$ \\
pLS1 & RP4 & ND & ND \\
pMV158 & None & $1.6 \times 10^{-6}$ & $2 \times 10^{-2}$ \\
pMV158 & pSU2007 (R388) & (R) \\
\hline
\end{tabular}

* The donor strain used was HMS174 and the values are expressed as transconjugants per donor cell.

with pMV158 DNA. As controls, we used the donor strain harbouring only RP4 or pMV158. In addition, the pMV158-derivative plasmid pLS1, which lacks the mobilization functions, was also used (see Fig. 1a). Mating experiments showed that pMV158 could be transferred at a moderate efficiency when plasmid RP4 was employed as the auxiliary plasmid (Table 2). Transfer of pMV158 was about 1000-fold less efficient than that of RP4. Analysis of the DNA content of six transconjugants showed the presence of pMV158 in all of them (not shown). No transconjugants were detected when only pMV158 was tested and, as expected, the $\Delta m o b M$ derivative plasmid pLS1 was not transferred (Table 2). We conclude that, in addition to plasmids of the Inc18 family, plasmid RP4 can provide the functions needed for conjugative mobilization of the streptococcal plasmid pMV158. At a similar low frequency, the IncW plasmid R388 (Datta \& Hedges, 1972) was also able to mobilize pMV158 (Table 2). However, under the same experimental conditions, pMV158 could not be mobilized by F (not shown). Transfer mediated by RP4 was also observed from E. coli to the Gram-positive host L. lactis, although at very low frequency $\left(2 \times 10^{-7}\right)$, indicating that the RP4 transfer machinery enables promiscuous plasmids, like pMV158, to surpass the socalled barrier between these two types of bacteria. The above finding may provide new tools for transferring DNA cloned into pMV158 among a variety of species in which this plasmid replicates (del Solar et al., 1998), although the efficiency of transfer should be improved.

\section{Functions of RP4 involved in pMV158 mobilization}

To know which functions of the auxiliary plasmids were involved in transfer, we made use of previously developed plasmid vectors which harbour all or part of the transfer machinery of RP4 (Balzer et al., 1994). The results (Table 3 ) showed that two of the RP4 derivatives were able to promote transfer of pMV158 with a high frequency, whereas plasmids defective in the $\operatorname{tra} G$ or traF genes (Pansegrau et al., 1994) failed to mobilize pMV158. Failure to mobilize the IncQ plasmid RSF1010 by plasmids harbouring essential mutations in these RP4-encoded genes has been reported (Balzer et al., 1994). We take this finding as an indication that both TraG and TraF functions are important for mobilization of pMV158 mediated by RP4. However, a detailed exploration of the possible interactions of MobM protein and those encoded by RP4 awaits further research. The mobilizing RP4 derivatives showed about 100- to 1000-fold increase in the frequency of pMV158 transfer compared with the wild-type RP4, a difference which may be ascribed to leakiness of the tac promoter which directs synthesis of the RP4-tra genes (Balzer et al., 1994). Transfer of pMV158 mediated by co-integration with RP4 (also termed conduction) could be

Table 3. Mobilization of pMV158

ND, None detected.

\begin{tabular}{|lcc|}
\hline Auxiliary plasmid & Relevant feature & $\begin{array}{c}\text { pMV158 mobilization } \\
\text { frequency* }\end{array}$ \\
\hline RP4 & Wild-type & $3 \cdot 5 \times 10^{-5}$ \\
pDB126 & Tra1, Tra2 & $4 \cdot 2 \times 10^{-2}$ \\
pDB127 & tra & $\mathrm{ND}$ \\
pDB128 & traI $^{-}$ & $4 \cdot 3 \times 10^{-3}$ \\
pDB129 & traF $^{-}$ & $\mathrm{ND}$ \\
\hline
\end{tabular}

*Frequencies expressed as in Table 2. 
Table 4. Mobilization of the oriT-containing plasmid pNLF4 by RP4 and PLGM2

$\mathrm{Cm}^{\mathrm{R}}$, chloramphenicol resistant; ND, none detected.

\begin{tabular}{|lcc|}
\hline $\begin{array}{l}\text { Concn IPTG } \\
(\mathbf{m M})\end{array}$ & $\begin{array}{c}\text { Time of IPTG } \\
\text { induction }(\mathbf{m i n})\end{array}$ & $\begin{array}{c}\text { Mobilization frequency } \\
\text { of pNLF4 }\left(\mathbf{C m}^{\mathrm{R}}\right)^{* *}\end{array}$ \\
\hline 0 & 30 & $\mathrm{ND}$ \\
$0 \cdot 10$ & 30 & $1 \times 10^{-6}$ \\
$0 \cdot 25$ & 30 & $2 \times 10^{-6}$ \\
$0 \cdot 50$ & 30 & $2 \times 10^{-5}$ \\
$1 \cdot 0$ & 30 & $3 \times 10^{-7}$ \\
$0 \cdot 50$ & 10 & $8.5 \times 10^{-5}$ \\
$0 \cdot 50$ & 30 & $1.5 \times 10^{-5}$ \\
$0 \cdot 50$ & 60 & $0 \cdot 8 \times 10^{-5}$ \\
\hline
\end{tabular}

* The donor strain was BL21(DE3). Frequencies as in Table 2.

considered as unlikely because: i) plasmid pDB128, which has a defective traI gene (the nickase of RP4) was able to mobilize pMV158 and ii) the donor strain HB101 is defective in the RecA recombination pathway. Similarly, the donor strain used in the R388-mediated transfer of pMV158 (DH5 $\alpha$ ) is also recA-defective. In this respect, it is interesting to point out that cointegration between pMV158 and the auxiliary plasmid pIP105, although unlikely, could not be discounted (Priebe \& Lacks, 1989).

\section{Cloning of pMV158-oriT: construction of pNLF4}

To define the functional pMV158-oriT, the DraITth111I DNA region of pMV158 was cloned into the vector plasmid pACYC184 (Fig. 1). This region includes the MobM-mediated nic site as well as the region where the DNase I footprints generated by MobM protein were defined (Grohmann et al., 1999; Guzmán \& Espinosa, 1997). Analysis and characterization of the plasmid content of several transformants allowed us to identify the desired construction. The resulting plasmid was termed pNLF4.

\section{Uncoupling of pMV158-oriT from the mobM gene: mobilization of pNLF4}

To assay the functionality of the cloned pMV158-oriT, the E. coli BL21(DE3)/pLGM2 strain was transformed with DNA from plasmids RP4 and pNLF4. The resulting strain contains, in addition to the cloned pMV158-oriT (pNLF4) and RP4 as the auxiliary plasmid, the pMV158mobM gene placed under the control of the $\phi 10$ promoter of phage T7 (plasmid pLGM2). Thus, synthesis of MobM is inducible by IPTG (Guzmán \& Espinosa, 1997), so that the intracellular levels of MobM should depend upon the amount of IPTG added to the cultures. The results of the mating experiments (Table 4) showed that the number of transconjugants increased with the IPTG concentration used, the optimum being

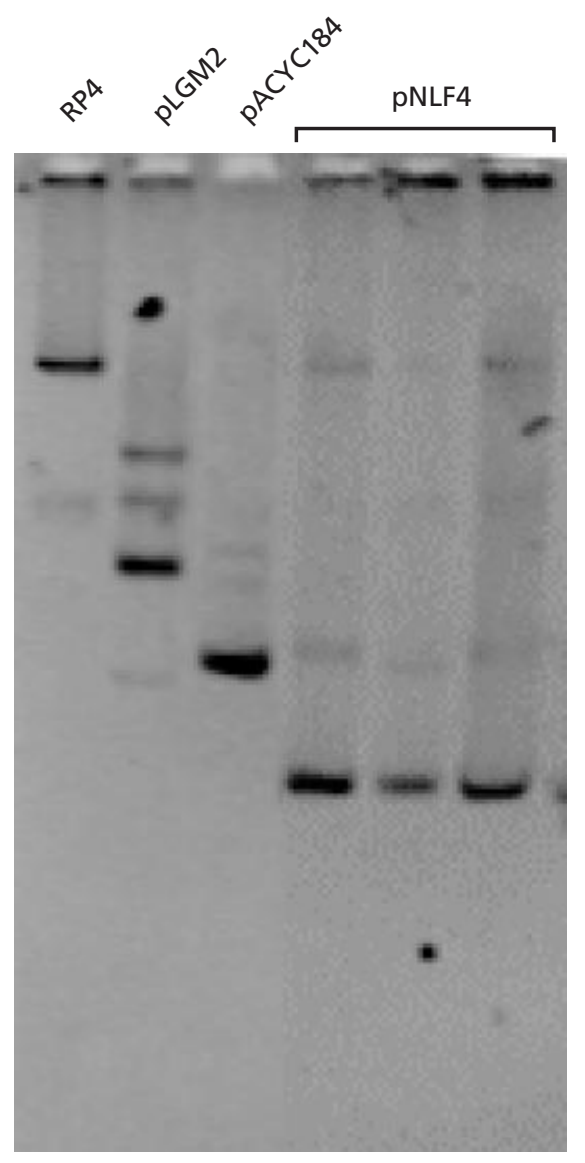

Fig. 2. Transfer of pNLF4 mediated by RP4 and pLGM2. Plasmid content of trans-conjugant clones (three rightmost lanes) were detected by agarose gel electrophoresis. They harboured pNLF4 and RP4. As controls, DNAs from plasmids (left to right) RP4, pLGM2 and pACYC184, isolated from the donor strain, were used. Note that the pACYC184 DNA forms are dimers.

$0.5 \mathrm{mM}$. At $1 \mathrm{mM}$ IPTG, a 100 -fold decrease in the frequency of conjugation was found, probably because overproduction of MobM could be toxic to the host harbouring pLGM2. Time of induction was also observed to be an important parameter for the transfer efficiency, the optimal period being $10 \mathrm{~min}$. The integrity of the mobilized plasmid pNLF4 was checked by analysis of the plasmid content of some of the transconjugants (Fig. 2). Most of the vector pACYC184, and part of plasmid pLGM2, appeared as dimers (Fig. 2), as deduced from restriction analysis of the plasmid DNA. In all cases analysed, simultaneous transfer of RP4 was observed (Fig. 2), probably because of the high frequency of RP4 conjugation (Table 2). Our results allow us to conclude that: i) the functional pMV158-oriT is encompassed between the 247 bp DraI-Tth111I DNA fragment, a region that contains the in vitro defined site where MobM protein introduces its nick on supercoiled pMV158 DNA (Guzmán \& Espinosa, 1997); and ii) MobM is not only acting in cis, but also behaves like a trans-acting protein. 


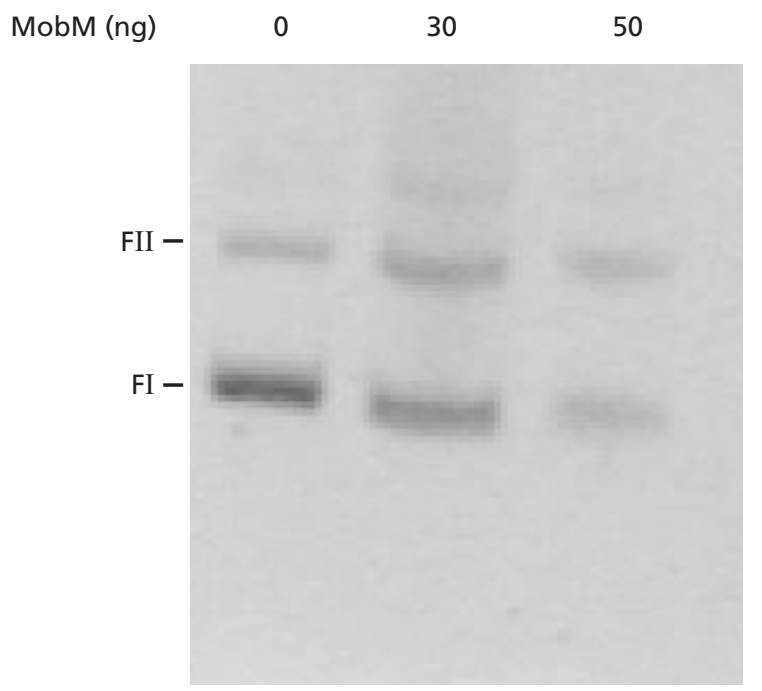

Fig. 3. In vitro nicking of pNLF4 by purified MobM protein. DNA from plasmid pNLF4, harbouring pMV158-oriT, was treated with purified MobM $(0,25$ and $50 \mathrm{ng})$. The position of supercoiled (FI) and of relaxed (FII) forms of the plasmid are indicated.

\section{In vitro activity of MobM protein on the pMV158- oriT cloned into pNLF4}

The nicking-closing initiator of pMV158 replication protein $\mathrm{RepB}$ recognizes, in addition to its own, origins of replication of related plasmids like the staphylococcal replicon $\mathrm{pE} 194$. However, this recognition demands that the target plasmid DNA should have an adequate degree of supercoiling (Moscoso et al., 1995). Based on the in vivo transfer of pNLF4 (Table 4), it was logical to assume that: i) supercoiling of this plasmid was adequate for MobM-mediated cleavage and ii) the cloned functional oriT should be a substrate for MobM. To test whether these assumptions were correct, supercoiled DNA from pNLF4 (200 ng) was incubated with purified MobM protein (25 and $50 \mathrm{ng}$ ) and the degree of relaxation was measured. The results (Fig. 3) showed that the pNLF4 DNA was a good substrate for cleavage by MobM, since the percentage of relaxed (FII) forms increased from $30 \%$ in the untreated samples to $50 \%$ in the presence of MobM. Under the same experimental conditions, the vector pACYC184 was not cleaved by MobM (not shown). Previous experiments showed that MobM-mediated conversion of FI to FII forms of pMV158 DNA reached up to 50\% (Guzmán \& Espinosa, 1997). Consequently, the pMV158-oriT cloned into foreign DNA was a good substrate for the in vitro cleavage mediated by MobM. Interestingly, MobM was also able to cleave supercoiled DNA from a derivative of the Streptococcus ferus plasmid pVA380-1 (LeBlanc et al., 1992), whose oriT exhibited several differences with respect to pMV158-oriT. However, the efficiency of MobM-mediated cleavage was lower than that found for its cognate origin of transfer (Grohmann et al., 1999).
The DNA region around the pMV158 nic site is conserved among a group of plasmids from Grampositive bacteria, but it exhibited weaker similarity with known nic sites of plasmids from Gram-negative bacteria (Guzmán \& Espinosa, 1997; Llosa et al., 1995). In addition, the mob/oriT regions of the mobilizable transposon Tn4555 from Bacteroides, and those of the so-called NBUs (non-replicating bacteroides units), share a high degree of homology with that of pMV158oriT/mobM, being considered members of the same evolutionary family (Smith et al., 1998). More recently, the oriT region of transposon Tn4451 from Clostridium perfringens has been shown to contain 14 conserved bases (within a stretch of 25 bases) with pMV158-oriT (Crellin \& Rood, 1998). It is worth pointing out that transfer of these elements to E. coli is feasible, but transfer from the E. coli donors requires the presence of a co-resident plasmid like RP4 (Murphy \& Mallamy, 1993). It would thus appear that mobile genetic elements have developed a genetic strategy by which they incorporate specific mobilization cassettes that facilitate their spread and, as a consequence, resistance to antibiotics among many bacterial species.

\section{ACKNOWLEDGEMENTS}

Thanks are due to E. Lanka and F. de la Cruz for providing us with plasmids and for helpful discussions. The help of M. T. Alda in some of the experiments and of members of our laboratory for helpful suggestions is acknowledged. We are thankful to colleagues within the EU-Concerted Action BIO4CT98-0099 for stimulating discussions. Research financed by CICYT (Grant BIO97-0347) and Comunidad Autónoma de Madrid (Grant 07B/30/99). M.E.F. is the recipient of an external post-doctoral fellowship of the CONICET (Argentina).

\section{REFERENCES}

Balzer, D., Pansegrau, W. \& Lamka, E. (1994). Essential motifs of relaxase (TraI) and TraG proteins involved in conjugative transfer of plasmid RP4. J Bacteriol 176, 4285-4295.

Bates, S., Roscoe, R. A., Althorpe, N. J., Brammar, W. J. \& Wilkins, B. M. (1999). Expression of leading region genes on IncI1 plasmid ColIb-P9: genetic evidence for single-stranded DNA transcription. Microbiology 145, 2655-2662.

Bertram, J., Strätz, M. \& Dürre, P. (1991). Natural transfer of conjugative transposon Tn916 between gram-positive and gramnegative bacteria. J Bacteriol 173, 443-448.

Bolland, S., Llosa, M., Avila, P. \& de la Cruz, F. (1990). General organization of the conjugal transfer genes of the IncW plasmid $\mathrm{R} 388$ and interactions between R388 and IncN and IncP plasmids. J Bacteriol 172, 5795-5802.

Burdett, V. (1980). Identification of tetracycline-resistant Rplasmids in Streptococcus agalactiae (group B). Antimicrob Agents Chemother 18, 753-760.

Campbell, J. L., Richardson, C. C. \& Studier, F. W. (1978). Genetic recombination and complementation between bacteriophage T7 and cloned fragments of T7 DNA. Proc Natl Acad Sci USA 75, 2276-2280.

Crellin, P. K. \& Rood, J. I. (1998). Tn4451 from Clostridium perfringens is a mobilizable transposon that encodes the functional Mob protein, TnpZ. Mol Microbiol 27, 631-642. 
Datta, N. \& Hedges, R. W. (1972). Trimethoprim resistance conferred by W plasmids in Enterobacteriaceae. J Gen Microbiol 72, 349-355.

Farías, M. E., Grohmann, E. \& Espinosa, M. (1999). Expression of the mobM gene of the streptococcal plasmid pMV158 in Lactococcus lactis subsp. lactis. FEMS Microbiol Lett 176, 403-410.

Grohmann, E., Zechner, E. L. \& Espinosa, M. (1997). Determination of specific DNA strand discontinuities with nucleotide resolution in exponentially growing bacteria harbouring rolling circle-replicating plasmids. FEMS Microbiol Lett 152, 363-369.

Grohmann, E., Guzmán, L. M. \& Espinosa, M. (1999). Mobilisation of the streptococcal plasmid pMV158: interactions of MobM protein with its cognate oriT DNA region. Mol Gen Genet 261, 707-715.

Guzmán, L. \& Espinosa, M. (1997). The mobilization protein, MobM, of the streptococcal plasmid pMV158 specifically cleaves supercoiled DNA at the plasmid oriT. J Mol Biol 267, 688-702.

Lacks, S. A., López, P., Greenberg, B. \& Espinosa, M. (1986). Identification and analysis of genes for tetracycline resistance and replication functions in the broad-host-range plasmid pLS1. J Mol Biol 192, 753-765.

Lanka, E. \& Wilkins, B. M. (1995). DNA processing reactions in bacterial conjugation. Annu Rev Biochem 64, 141-169.

LeBlanc, D. J., Lee, L. N. \& Abu-Al-Jaibat, A. (1992). Molecular, genetic, and functional analysis of the basic replicon of pVA3801, a plasmid of oral streptococcal origin. Plasmid 28, 130-145.

van der Lelie, D., Wosten, H. A. B., Bron, S., Oskam, L. \& Venema, G. (1990). Conjugal mobilization of streptococcal plasmid pMV158 between strains of Lactococcus lactis subsp. lactis. J Bacteriol 172, 47-52.

Llosa, M., Grandoso, G. \& de la Cruz, F. (1995). Nicking activity of TrwC directed against the origin of transfer of the IncW plasmid R388. J Mol Biol 246, 54-62.

Masai, H. \& Arai, K. (1997). Frpo: a novel single-stranded DNA promoter for transcription and for primer RNA synthesis of DNA replication. Cell 89, 897-907.

Moscoso, M., del Solar, G. \& Espinosa, M. (1995). In vitro recognition of the replication origin of pLS1 and of plasmids of the pLS1 family by the RepB initiator protein. J Bacteriol 177, 7041-7049.

Murphy, C. G. \& Mallamy, M. H. (1993). Characterization of a 'mobilization cassette' in transposon Tn4399 from Bacteroides fragilis. J Bacteriol 175, 5814-5823.

Pansegrau, W. \& Lanka, E. (1996). Enzymology of DNA strand transfer by conjugative mechanisms. Prog Nucleic Acid Res Mol Biol 54, 197-251.

Pansegrau, W., Lanka, E., Barth, P. T. \& 7 other authors (1994). Complete nucleotide sequence of Birmingham IncP $\alpha$ plasmids: compilation and comparative analysis. J Mol Biol 239, 623-662.

Priebe, S. D. \& Lacks, S. A. (1989). Region of the streptococcal plasmid pMV158 required for conjugative mobilization. $J$ Bacteriol 171, 4778-4784.

Sambrook, J., Fritsch, E. F. \& Maniatis, T. (1989). Molecular Cloning: a Laboratory Manual, 2nd edn. Cold Spring Harbor, NY : Cold Spring Harbor Laboratory.

Smith, C. J., Tribble, G. D. \& Bayley, D. P. (1998). Genetic elements of Bacteroides species: a moving story. Plasmid 40, 12-29.

Smith, M. D., Shoemaker, N. B., Burdett, V. \& Guild, W. R. (1980). Transfer of plasmids by conjugation in Streptococcus pneumoniae. Plasmid 3, 70-79.

del Solar, G., Díaz, R. \& Espinosa, M. (1987). Replication of the streptococcal plasmid pMV158 and derivatives in cell-free extracts of Escherichia coli. Mol Gen Genet 206, 428-435.

del Solar, G., Giraldo, R., Ruiz-Echevarría, M. J., Espinosa, M. \& Díaz-Orejas, R. (1998). Replication and control of circular bacterial plasmids. Microbiol Mol Biol Rev 62, 434-464.

Trieu-Cuot, P., Arthur, M. \& Courvalin, P. (1987). Plasmid transfer by conjugation from Escherichia coli to gram-positive bacteria. FEMS Microbiol Lett 48, 289-294.

Wang, A. \& Macrina, F. L. (1995). Characterization of six linked open reading frames necessary for pIP501-mediated conjugation. Plasmid 34, 206-210.

Received 3 February 2000; revised 5 June 2000; accepted 20 June 2000 